\title{
Communications
}

\section{Regiospecific Addition of Alkyl and Allyl Groups to $\alpha, \beta$-Unsaturated Carbonyl Compounds with Trialkylboranes through the Palladium Catalyst}

\author{
Chung Min Park, Sam Yong Han, Nan Young Seo, Chang-ho Byun, and Young Soo Gyoung* \\ Department of Chemistry, Kangming National University, Gangming, Gangwon 210-702, Korea. E-mail: gus@kangming.ac.kr \\ Received July 24, 2006
}

Key Words : $\alpha, \beta$ Unsaturated carbonyl compounds. Trialkylboranes, Palladium, Three component coupling

\begin{abstract}
Trialkylboranes were well known to transfer an alky] group to the $\beta$-position of $\alpha \beta$-unsaturated aldehydes and ketones through radical chain mechanism. ${ }^{12-d}$ It is reported that trialkylborane reacted with acrolein, ${ }^{2 a} \alpha$-methylacrolein, ${ }^{2 b} \alpha$ bromolacrolein, ${ }^{2 c}$ methyl vinyl ketone, ${ }^{25} 2$ methylcycloalkanones ${ }^{2 \mathrm{~d}}$ and isopropenyl methyl ketone $\mathrm{e}^{2 \mathrm{e}}$ to generate 1,4-addition products via hydrolysis of enol borinate intermediate with water: Mukaiyama reported for preparation of $\beta$-hydroxyketones by the reaction of vinyloxyboranes and carbonyl compounds..$^{3}$ Quite recently, Yamamoto reported $\beta$-alkyl- $\alpha$-allylation of benzylidenmalononitrile using trialkylboranes and $\pi$-allylpalladium. ${ }^{4}$ However such enol borinates were used only limited scope as a synthetic intermediates. In this paper, we wish to report that the generated enol borinate with $\alpha, \beta$-unsaturated carbonyl compounds can be used as good nucleophiles for the reaction with $\pi$-allylpalladium intermediates. The alkyl radical from 2 undergo 1,4-addition at the $\beta$-position of olefins and form an enol borinate. And generated enol borinate intermediate added to the $\pi$-allylpalladium of allyl compound and palladium. The reaction gave the $\beta$-alkyl and $\alpha$-allylated derivatives of the activated olefins in a direct process, with high to good yields (eq 1). The results are summarized in Table 1.
\end{abstract}

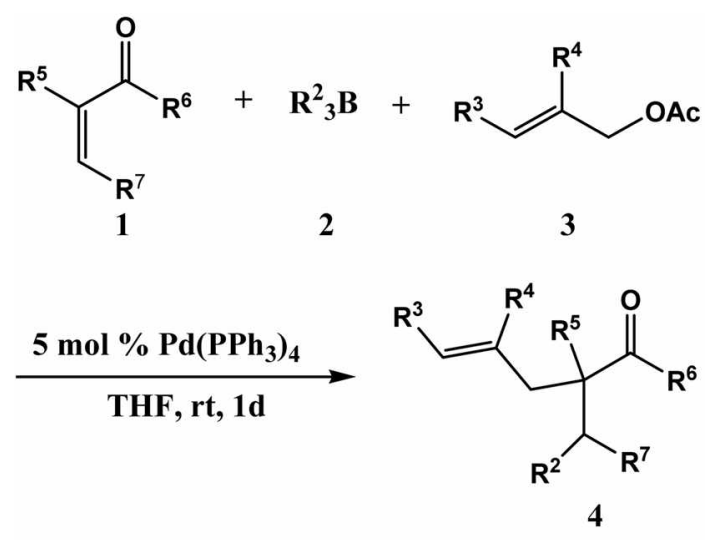

The reaction of methacrolein 1 a with tributylborane 2 a and allyl compounds $(\mathbf{3 a}, \mathbf{3 b}, \mathbf{3 c})$ at room temperature in the presence of $\mathrm{Pd}\left(\mathrm{PPh}_{3}\right)_{4}(5 \mathrm{~mol} \%)$ in THF for I day gave corresponding alkyl-allyl products $4 \mathbf{a}, \mathbf{4 b}$ and $\mathbf{4 c}$, respectively, in good yields (entries 1,2, and 3). As a result of extensive examination of various allyl compounds, we found that the $\alpha, \beta$-unsaturated carbonyl compounds 1 with allylic acetates 3 proceeded very smoothly at room temperature in the presence of $\mathrm{Pd}\left(\mathrm{PPh}_{3}\right)_{4}$ catalyst in $\mathrm{THF}$ to give the corresponding $\beta$-alkylated and $\alpha$-allylated products $\mathbf{4}$ in high yields. Treatment of tricyclohexylborane $2 \mathrm{~b}$, which made in situ, with 1 a under the nomal conditions gave the desired products (4d-1) in good to moderate yield (entry 4-6). However the reaction of acrolein $\mathbf{l b}$, methyl vinyl ketone $1 \mathrm{c}$ and 2-cyclohexen-1-one 1d, which bear no substituent at $\beta$ position, gave the desired products $\mathbf{4 g}, \mathbf{4 h}$ and $\mathbf{4 i}$ in $37 \%$, $27 \%$ and $12 \%$ yield (entries 7,8 and 9 ). These poor yields indicate that the radical unstableness of the intermediate 5 which are not attached $\mathrm{R}^{5}$ group at $\beta$ position. The sterical bulky olefin le, derived from Meldrum's acid, gave only the alkylated product $\mathbf{4 j}$ in $50 \%$ yield (entry 10 ).

According to transfer an alkyl group for producing $\beta$ alkylation of $\alpha \beta$-unsaturated carbonyl compound $\mathbf{1}$, the reaction reported that it involved a free-radical mechanism. Under this free-radical mechanism regarding the alkylation, it was expected for the $\alpha$-allylation via $\pi$-allylpalladium that the reaction continuously proceeds the same path through the initially formed intermediate of the enol borinate 5 (eq. 2). Although the exact path of the mechanism involving the free-radical reaction is still unclear, some cruses may be<smiles>[R7]C=C([R3])C([R6])=O</smiles>

5 
Table 1. $\beta$-Alkyl- $\alpha$-allylation of $\alpha, \beta$-unsaturated carbonyl compounds

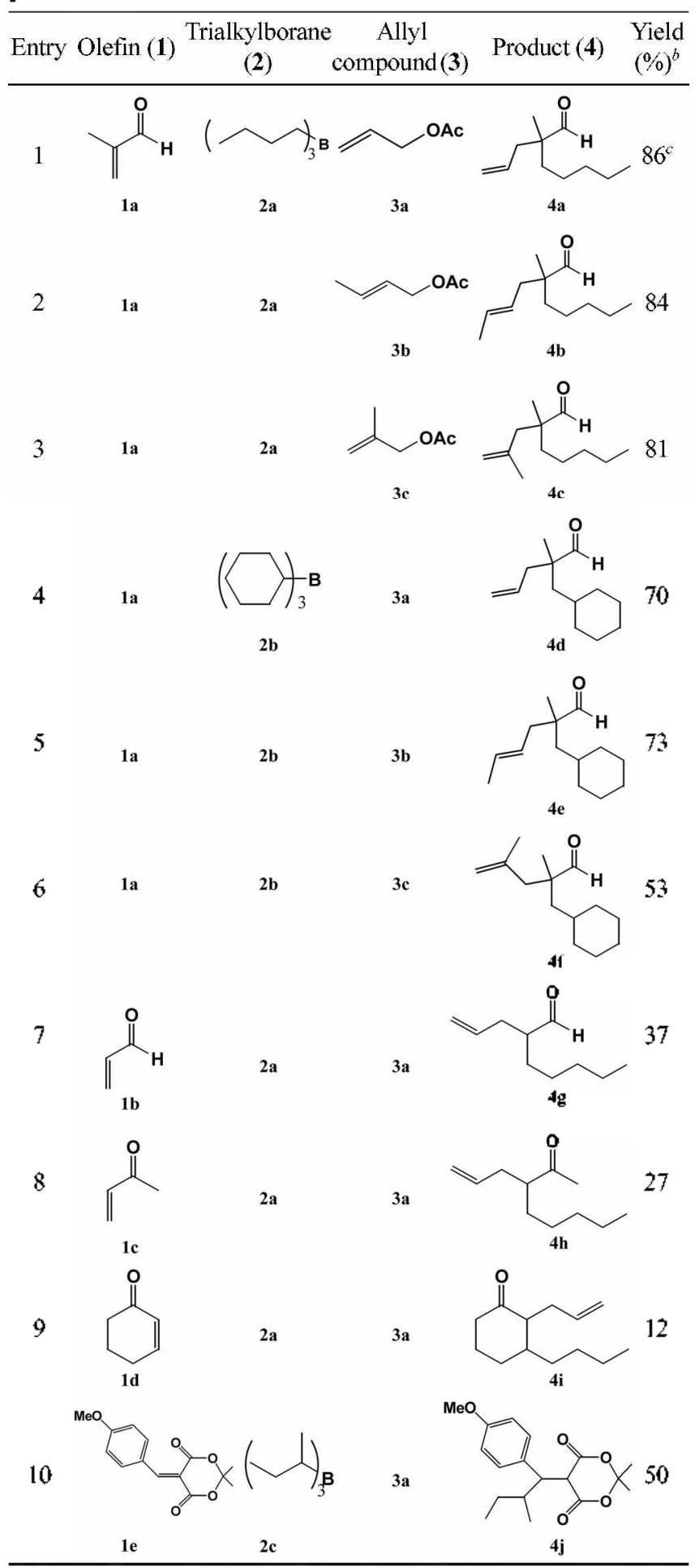

Tnless otherwise noled, all the reactions were conducted with olefin ( $0.8 \mathrm{mmol})$, trialkylborane $(0.88 \mathrm{mmol})$ and allyl compound $(2.0 \mathrm{mmol})$ in the presence of $\mathrm{Pd}\left(\mathrm{PPh}_{3}\right)_{4}(5 \mathrm{~mol} \%)$ in $1.5 \mathrm{~mL}$ TJT at $\mathrm{rt}$ for $1 \mathrm{~d}$. Tields were obtained after purification by column chromatography. ${ }^{c}$ Tributylborane contains 6\% sec-bulyl group and the addition product have $6 \%$ of sec-butyl group.

revealed that the better reaction yield depends on the $\beta$ alkylation procedure by trialkylboranes and a problem of dropping in products yield arise where the intermediate $\mathbf{5}$ have the order of radical stability, ${ }^{6}$ when using $\alpha, \beta$ unsaturated carbonyl compounds which are not attached $\mathrm{R}^{3}$ group.

In conclusion, we have developed an easy synthetic methodology to make double-added products of the olefins in a direct process by palladium catalyzed reaction. In these reactions, the use of $\alpha, \beta$-unsaturated carbonyl compounds with tiralkylboranes would afford smoothly alkylated intermediates 5 under neutral conditions. Directly, palladium catalyzed reaction with $\mathbf{5}$ gave the corresponding $\beta$-alkyl and $\alpha$-allylated products. The ordinary coupling reactions by organoboron compounds was utilized for the three-component coupling reactions.

Acknowledgement. This work was supported by grant No. RTI05-01-02 from the Regional Technology Innovation Program of the Commerce, Industry and Energy (MOCIE).

\section{References}

I. (a) Cragg, G. M. L. Organoboranes in Organic Sintheses; Marcel Dekker, INC.: New York, U. S. A., 1973; p 253. (b) Brown, H. C. Organic Symheses via Boranes; John Wiley \& Sons: New York, U. S. A., 1975; p 146. (c) Pelter, A.; Sinith, K.; Brown, H. C. Borane Reagent; Academic Press: London, U. K., 1988; p 92. (d) Onak, T. Organoborane Chemistry; Academic Press: New Yolk. U. S. A., 1975; p 108.

2. Brown, H. C.; Rogic, M. M.; Ratheke, M. W.; Kabalka, G W. (a) J. Am. Chem. Soc. 1967, 89, 5709. (b) 1968, 00, 4165. (c) 1968, 90,4166 . (d) $1969,91,2150$. (e) $1969,91,2147$.

3. Mukaiyama, T.; Inomata, K.; Mukai, M. J. An. Chent. Soc. 1973, 95,6409 .

4. Patil, T. P.; Hua, G.; Yamamoto, Y. J. Org. Chem, 2006, 7l, 2503.

5. Kabalka, G. W.; Brown, H. C.; Suzuki, A.; Honma, S.; Arase, A.; Itoh. M. J. Am. Chent. Soc. 1970, 92.710.

6. (a) Franz, J. A.; Suleman, N. K.; Alnajjar, M. S. J. Org. Cheni. 1986, 51, 19. (b) Troman, A. F.; Dikenson, D. A. Adv Free Radical Chem. 1965, $1, \mathrm{l}$.

7. General Procedure: An oven-dried $5 \mathrm{~mL}$ conical reaction vial containing a magnetic spin vane with argon inlet was charged with 1.2 equiv of tributylborane $2 \mathrm{a}(0.88 \mathrm{mmol}), 1.5 \mathrm{~mL}$ of freshly distilled THF and a $\alpha \beta$-unsaturated carbonyl compound la-e $(0.8$ mmol). For using tricyclohexylborane $\mathbf{2 d}$, an oven-dried $10 \mathrm{~mL}$ branched round flask, fitled with an inlet carrying a rubber septum cap, a magnetic stirring bar, and a condenser, was flushed with argon. In the flask was charged with $0.88 \mathrm{mmol}$ of borane in $2 \mathrm{~mL}$ of THF. Then cyclohexene $(2.64 \mathrm{mmol})$ was added and the mixture was stirred at $50^{\circ} \mathrm{C}$ for $3 \mathrm{hr}$ to ensure completion of this exceptionally sluggish hydroboration. Another oven-dried vial was charged with $0.5 \mathrm{~mol} \% \mathrm{Pd}\left(\mathrm{PPh}_{3}\right)_{4}(0.04 \mathrm{mmol}), 2$ equiv. of allyl acetate ( $1.6 \mathrm{mmol}$ ), $1.5 \mathrm{~mL}$ of THF for completely dissolved solution. To the colorless solution containing trialbutylborane was added the yellow solution containing palladium catalyst at room temperature. After being stirred for I day, the reaction mixture was filtered through a short silica gel column chromatography using ether as an eluent, and the filtrate was concentrated, the reaction was washed with cold $\mathrm{H}_{2} \mathrm{O}(3 \times 15 \mathrm{~mL})$, followed by three portions $15 \mathrm{~mL}$ of $\mathrm{H} \rightarrow \mathrm{O}$ saturated with sodium chloride. The organic layer was separated and the aqueous layer was extracted with diethyl ether $(3 \times 10 \mathrm{~mL})$. The combined organic extracts were dried over anhydrous $\mathrm{MgSO}_{4}$ and were concentrated in vacuum to give a crude oil. The crude product was purified via column chromalography with a mixed solvent $(n-H$ exane/EtOAc, $10 / 1)$. 